Research Article

\title{
Experimental Investigation on Short Concrete Columns Reinforced by Bamboo Scrimber under Axial Compression Loads
}

\author{
Min Lei $\mathbb{D}$, Zihao Wang, Penghui Li, Liyi Zeng, Hongyao Liu, Zhidong Zhang, \\ and Huicheng Su \\ Departments of Civil Engineering, Central South University of Forestry and Technology, Changsha 410000, China \\ Correspondence should be addressed to Min Lei; 26788829@qq.com
}

Received 24 May 2020; Revised 14 July 2020; Accepted 16 September 2020; Published 30 September 2020

Academic Editor: Hui Yao

Copyright (c) 2020 Min Lei et al. This is an open access article distributed under the Creative Commons Attribution License, which permits unrestricted use, distribution, and reproduction in any medium, provided the original work is properly cited.

\begin{abstract}
The paper presents bamboo scrimber bars as a reinforcing material instead of steel reinforcement in low-strength concrete columns. Twelve short concrete columns with different reinforcements are tested under axial compression load to study the axial compressive behavior of short concrete columns reinforced by bamboo scrimber. Three columns are reinforced concrete columns, and the other nine columns are bamboo scrimber reinforced concrete columns. The failure process, bearing capacity, axial deformation, and strain of the specimens are compared and analyzed. The results show that the bonding performance between the bamboo scrimber bars by surface treatment and low-strength concrete is excellent. In low-strength concrete columns, the material properties of bamboo bars play more thoroughly than those of steel bars. When the bamboo reinforcement ratio is increased, the concrete column ductility is significantly improved, but the bearing capacity of the concrete column is not increased. The bamboo scrimber bars with the size of $10 \mathrm{~mm} \times 10 \mathrm{~mm}$ or $15 \mathrm{~mm} \times 15 \mathrm{~mm}$ can be used as longitudinal bars of low-strength concrete columns. The ductility of the short concrete column with $2.56 \%$ bamboo scrimber reinforcement is close to that of the short concrete column with $0.72 \%$ steel reinforcement.
\end{abstract}

\section{Introduction}

The reinforced concrete structure is currently used extensively. Steel bars play a significant role in concrete structures. However, high pollution, high energy consumption, and nonrenewable nature and high prices of steel bars have led scholars to find out alternative materials to substitute steel bars in concrete structures $[1,2]$.

Bamboo has high tensile strength and low cost and is fast growing, renewable, environmentally friendly, and widely distributed globally. Research on the application of bamboo instead of steel bars in concrete structures began at the beginning of the $20^{\text {th }}$ century [3]. Leelatanon et al. [4] pointed out that $1.6 \%$ of the reinforcing steel could be replaced by $3.2 \%$ of the reinforced bamboo treated with Sikadur-31CFN in the concrete column. Terai and Minami [5] conducted bending tests of bamboo reinforced concrete beams and axial compression tests of bamboo reinforced concrete columns. The studies indicated that the cracking pattern of bamboo reinforced concrete beams is similar to reinforced concrete beams, and the ductility of bamboo reinforced concrete columns mainly depends on the strength of concrete. Agarwala et al.'s [6] research found that the bonding performance of bamboo bars and concrete after the binder treatment has been greatly enhanced, and the bearing capacity and ductility of bamboo bar concrete columns and bamboo bar concrete beams have been greatly improved. Huang et al. [7] studied the mechanical properties and influencing factors of bamboo reinforced concrete columns with different treatment methods and different bamboo reinforcement ratios under monotonic load with different eccentricity. Javadian et al. [8] proposed a method for making a bamboo bar composite. The bamboo bar composite can improve the defects of the natural bamboo bar; after being treated with epoxy coating and sanding, the bonding strength with concrete is greatly enhanced. The above research works show that it is possible to use bamboo bars to substitute steel bars in the concrete structure. 
However, natural bamboo has a few defects, such as durability, water absorption, and shrinkage. Moreover, the natural bamboo's performance of different regions, different kinds, and different parts is quite different. Wang [9] successfully produced the bamboo scrimber by hot pressing in the laboratory. The bamboo scrimber has uniform mechanical properties, small variability, high strength, excellent durability, and rare shrinkage, warpage, and cracking. Sharma et al. [10] found that the performance of bamboo scrimber is better than laminated bamboo, and the mechanical properties of the two types of bamboo are comparable to that of timber. Huang et al. [11] obtained the tensile, the compression, the shear modulus, and the corresponding stress-strain relationship of bamboo scrimber. Liu et al. [12] proposed that bamboo scrimber bars could replace steel bars and were used to strengthen low-cost masonry houses in rural areas.

The bamboo scrimber is an ideal engineering material. At present, there are approximately 110 million tons of idle bamboo resources in China. In Chinese rural areas, there are numerous low-cost dwellings. These dwellings are mostly self-built masonry structures. Since there is no standardized design and construction, the concrete strength of these masonry constructional columns is often low. The constructional column is mainly a constructional measure in the masonry structure, not the bearing member. Bamboo scrimber bars replace steel bars in this member, which not only saves energy and protects the environment, but also reduces the cost and meets the needs of economic development in rural areas. In this paper, axial compression tests of twelve short concrete columns are conducted to research the compressive bearing capacity and ductility of the columns, and the cooperative performance of the bamboo scrimber bars and low-strength concrete.

\section{Experimental Program}

2.1. Specimen Design. All columns have $250 \mathrm{~mm} \times 250 \mathrm{~mm}$ cross section in area and $750 \mathrm{~mm}$ in height, and the designed concrete strength is C10. A total of twelve columns are divided into four groups, and each group has three specimens. The group GJ is steel-reinforced concrete columns, and the groups ZJA, ZJB, and ZJC are bamboo scrimber reinforced concrete columns. The properties of the specimens are given in Table 1, and the details of the specimens are shown in Figure 1.

2.2. Specimen Preparation. Bamboo scrimber bars are cut from bamboo scrimber plates produced by Taohuajiang Bamboo Development Co., Ltd. in Yiyang city, China. The cross section of bamboo bars is $10 \mathrm{~mm} \times 10 \mathrm{~mm}$, $15 \mathrm{~mm} \times 15 \mathrm{~mm}$, and $20 \mathrm{~mm} \times 20 \mathrm{~mm}$, and the length of bamboo bars is $700 \mathrm{~mm}$. Some bamboo bars are affixed with strain gages. Then all bamboo bars are treated with epoxy resin. After the epoxy resin is semidried, sand was evenly spread on the surface of the bamboo bars to enhance the bonding property between the bamboo bars and concrete. Figure 2 shows the production process of bamboo scrimber strips.
After the treated bamboo bars are placed indoors for 24 hours, the longitudinal bamboo bars and stirrups are tied with 20 \# steel wire to form a bamboo cage. Each column is divided into three times of pouring, the height of concrete poured each time is $250 \mathrm{~mm}$, and the interval between each pouring time is not greater than 1 hour. The vibrating rod is used to vibrate the concrete in time to ensure that the upper and lower layers of concrete are tightly combined. These specimens are demolded after $24 \mathrm{~h}$ and then cured for 28 days. Before the test, the column surface is painted with white lime, which is convenient to observe the failure process of the specimens.

2.3. Material Properties. According to the testing methods for physical and mechanical properties of bamboo used in building [13], the material properties of bamboo scrimber are tested. Test details and some mechanical properties of the bamboo scrimber are given in Table 2. The material experiments of bamboo scrimber can be seen in Figure 3.

After being cured for 28 days, concrete test blocks were tested for compressive strength. For specimens GJ, ZJA, ZJB, and ZJC, the measured concrete strength is $8.6 \mathrm{MPa}$, 8.6 $\mathrm{MPa}$, 9.63 $\mathrm{MPa}$, and 7.62 $\mathrm{MPa}$, respectively.

\subsection{Test Scheme}

2.4.1. Test Equipment. The experiments are conducted in the structure test hall of Civil Engineering College, Central South University of Forestry and Technology. Figure 4 shows the loading device of the specimens. Vertical loads are applied through a hydraulic jack of $2000 \mathrm{kN}$ capacity. Between the jack and the force sensor, one steel plate ( $225 \mathrm{~mm}$ wide $\times 225 \mathrm{~mm}$ long $\times 40 \mathrm{~mm}$ thick) is placed. One same steel plate is placed between the force sensor and the beam of the reaction force frame, which can avoid stress concentration of the beam. In order to ensure that the specimen is compressed axially, the specimen is centered between two spherical bearings.

2.4.2. Loading Scheme. After centering the specimen, preload 1 or 2 load steps, and observe whether the instrument is functioning correctly. During formal loading, $10 \%$ of the estimated bearing capacity at one loading step is applied to the specimen, and each loading step is held for 3 minutes. When the specimen is near the peak load, reduce the loading step appropriately. When the axial load is gradually reduced below $85 \%$ of the peak load, the test is ended.

2.4.3. Measurement Scheme. The strain gages of BX 120$3 \mathrm{AA}$ are stick on the top, middle, and bottom of the longitudinal steel bars, and the strain gages of BX 120-50AA are stick on the top, middle, and bottom of the longitudinal bamboo bars. In the middle of the central axis of the four sides of the column, the strain gages (BX 120-100AA) are vertically attached. Two displacement meters are arranged 
TABle 1: Properties of specimens.

\begin{tabular}{|c|c|c|c|c|c|}
\hline \multirow{2}{*}{ Specimen group } & \multicolumn{4}{|c|}{ Longitudinal reinforcement } & \multirow{2}{*}{ Stirrup } \\
\hline & Type & Size $(\mathrm{mm})$ & Number & Reinforcement ratio (\%) & \\
\hline GJ & Steel & $\mathrm{C} 12$ & 4 & 0.72 & A6@100 \\
\hline ZJA & Bamboo & $10 \times 10$ & 4 & 0.64 & A6@100 \\
\hline ZJB & Bamboo & $15 \times 15$ & 4 & 1.44 & A6@100 \\
\hline ZJC & Bamboo & $20 \times 20$ & 4 & 2.56 & A6@100 \\
\hline
\end{tabular}
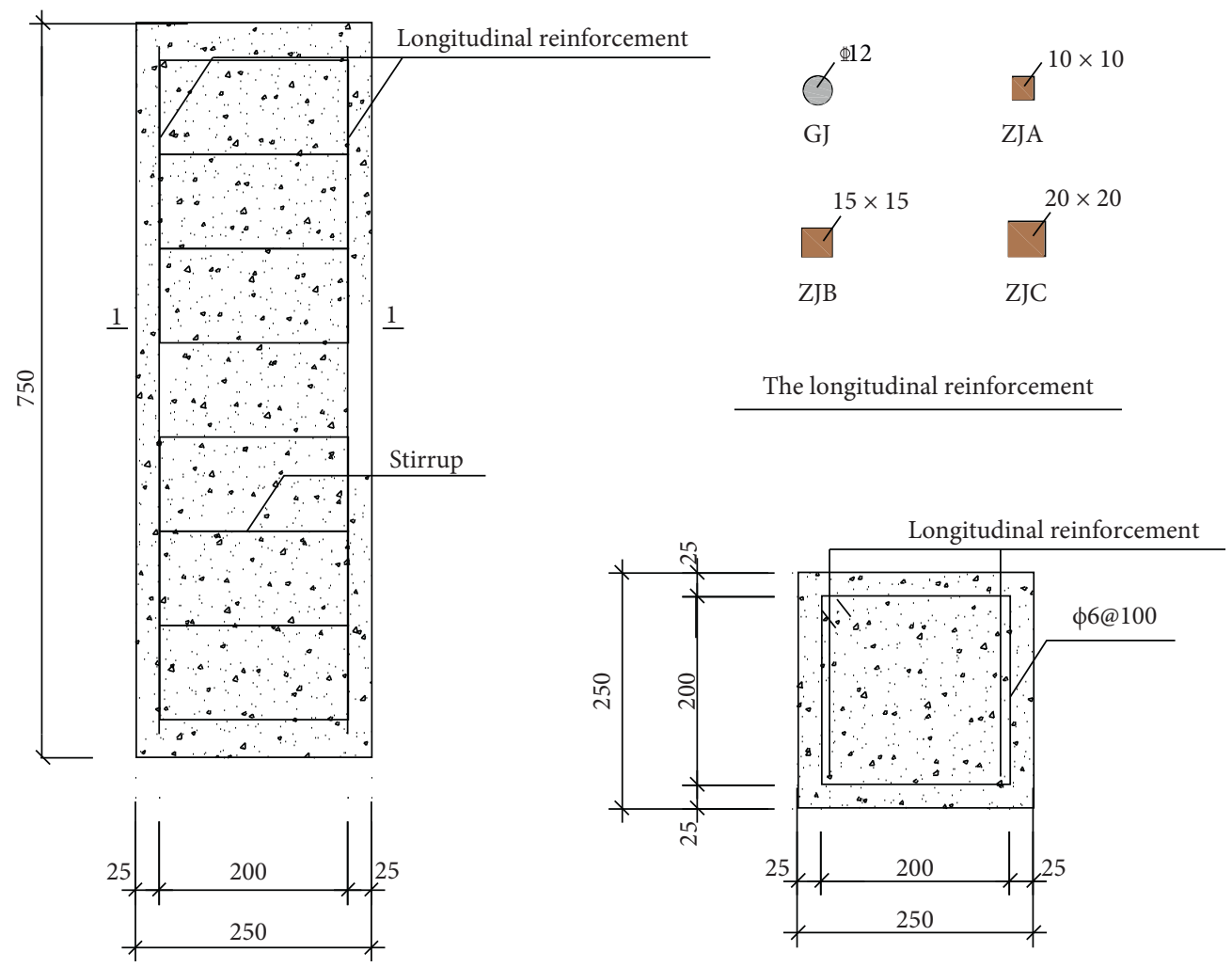

The longitudinal section

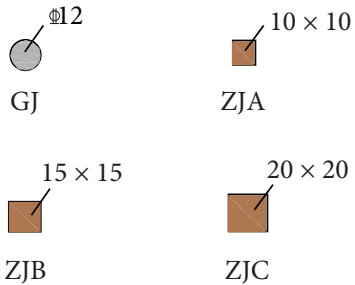

The longitudinal reinforcement

Figure 1: Details of specimens (all dimensions are in $\mathrm{mm}$ ).

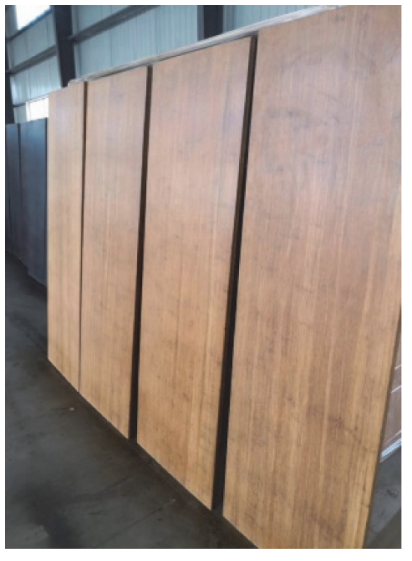

(a)

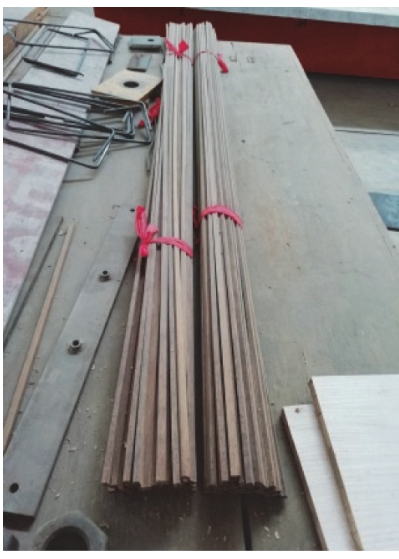

(b)

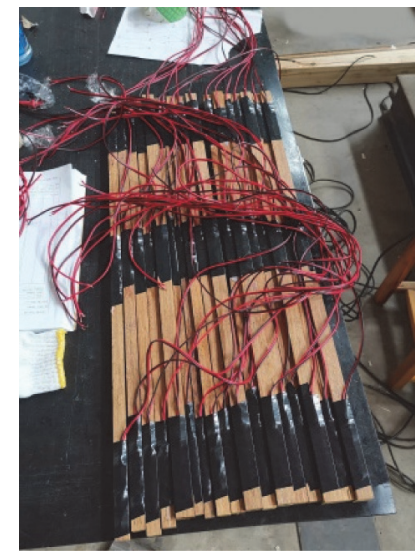

(c)

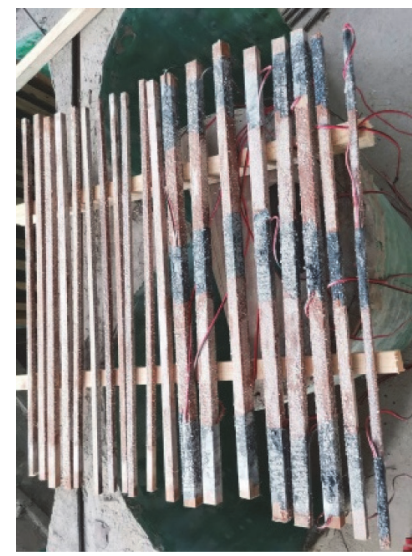

(d)

Figure 2: Production process of bamboo scrimber strips: (a) bamboo boards, (b) bamboo strips, (c) gluing strain gages, and (d) gluing sand. 
TABle 2: Test details and results of bamboo scrimber.

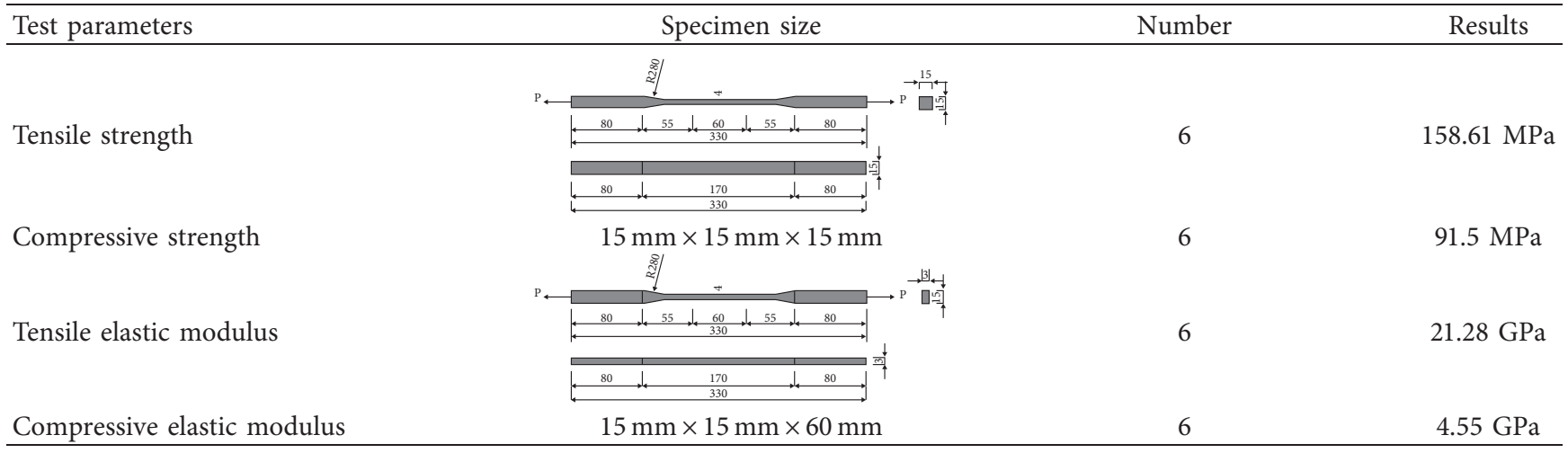

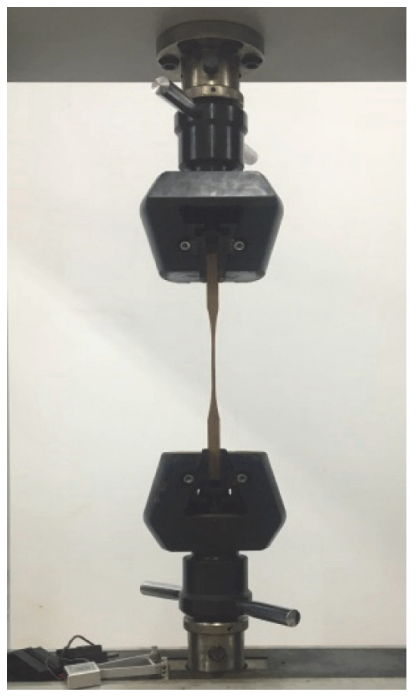

(a)

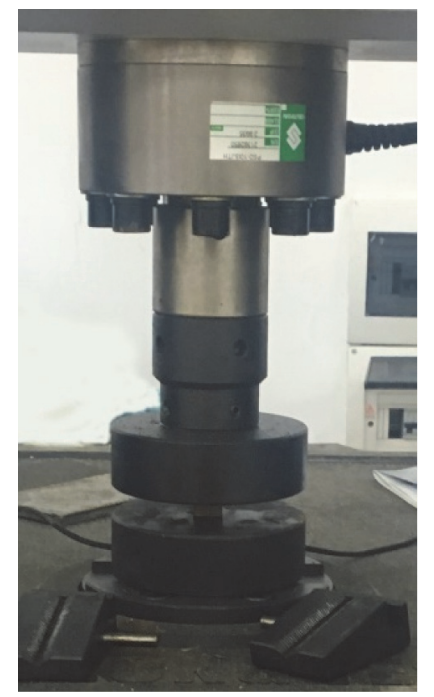

(b)

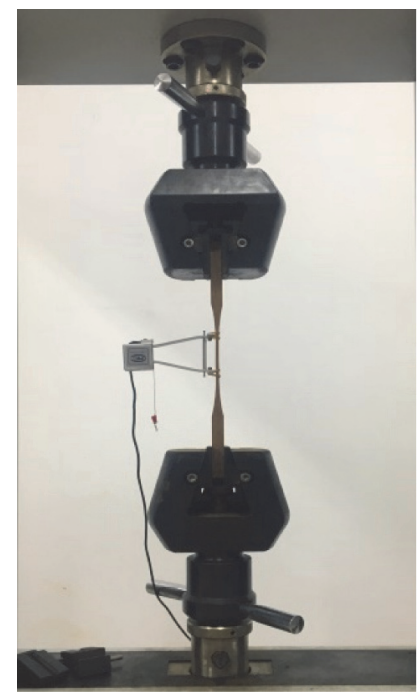

(c)

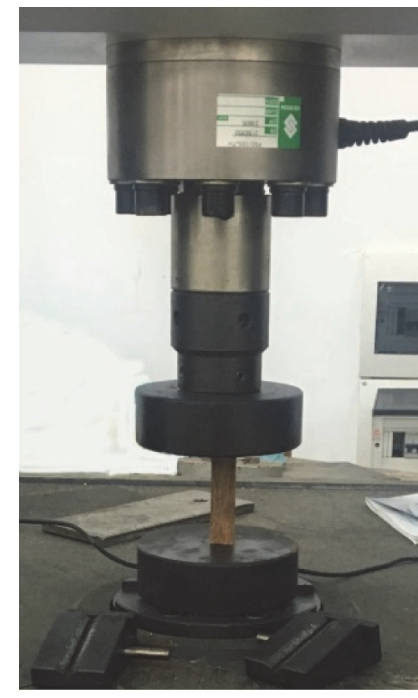

(d)

FIgURe 3: Material experiments of bamboo scrimber: (a) tensile strength, (b) compressive strength, (c) tensile elastic modulus, and (d) compressive elastic modulus.

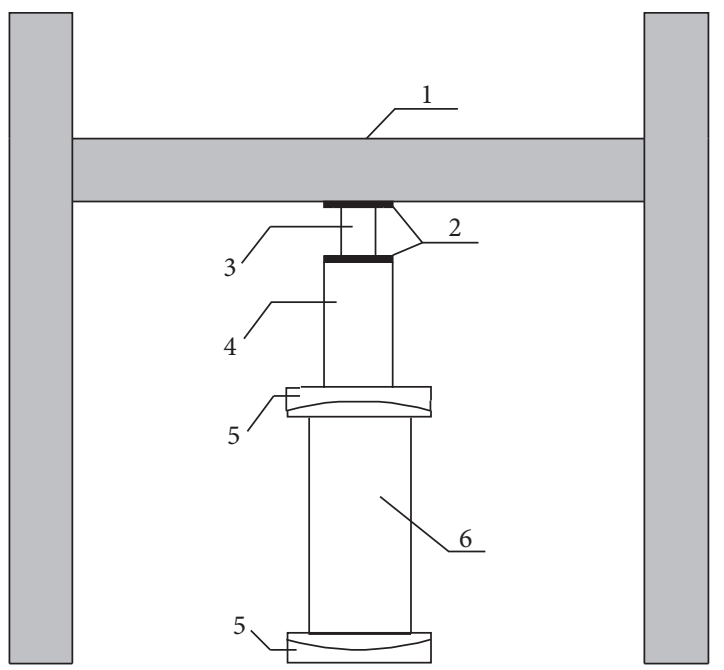

FIGURE 4: Loading device of specimens. (1) Reaction frame. (2) Steel plate. (3) Force sensor. (4) Jack. (5) Spherical bearing. (6) Specimen. on the bottom surface of the upper spherical bearing to measure the axial deformation of the specimen. Figure 5 shows the layout of measuring points.

\section{Test Results and Discussion}

3.1. Failure Modes. Figure 6 shows the failure crack patterns of specimens GJ under axial compression loads. At first, several tiny cracks appear on the top of the columns at about $60 \%$ of the peak load. As the load increases, multiple vertical cracks appear and extend downward. The cracks are concentrated in the upper section of the column. When getting to the peak load, the vertical cracks extend to the middle of the column. When the column is destroyed, concrete at the upper part of the column is crushed, and the steel bars do not yield.

The failure patterns of specimens ZJA are shown in Figure 7 . When the axial load reaches $75 \%-80 \%$ of the peak load, initial cracks appear at the upper end of the column. With the load increasing, several new cracks appear, and the 


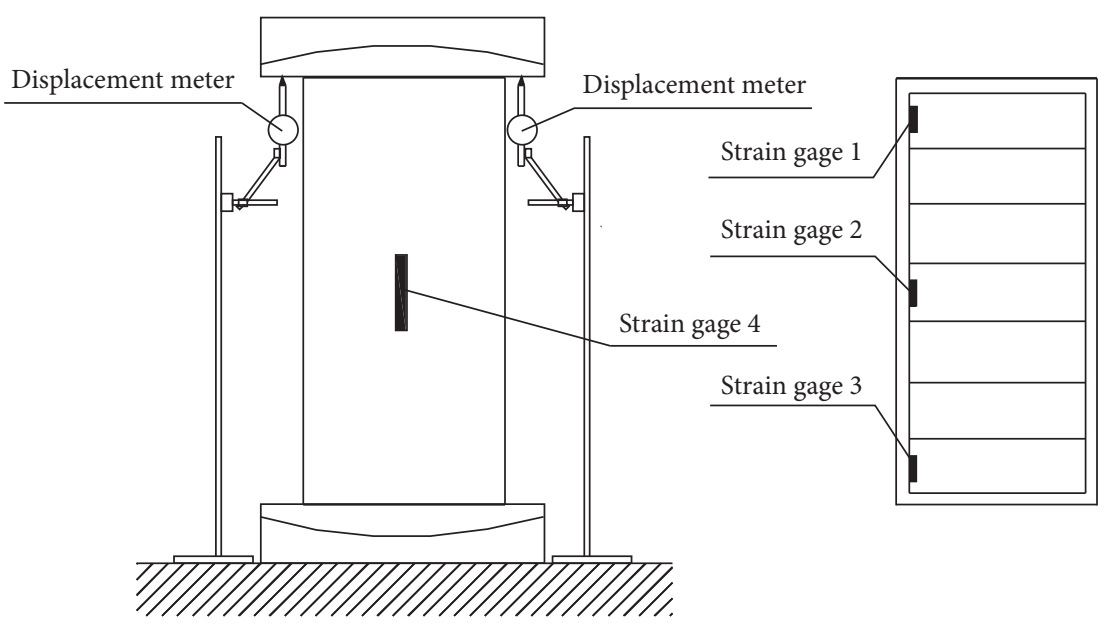

Figure 5: Layout of measuring points.

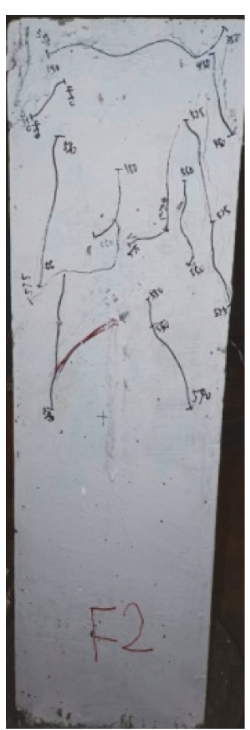

(a)

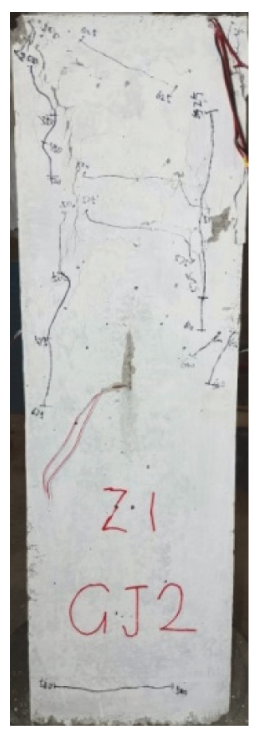

(b)

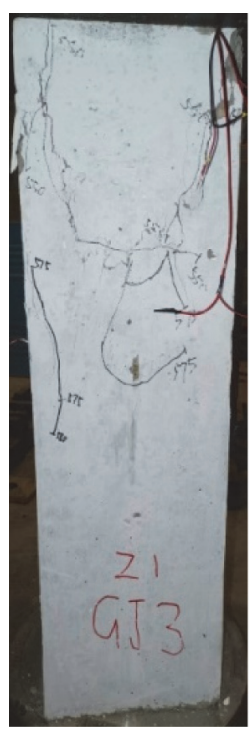

(c)

FIGURE 6: Failure crack pattern of specimens GJ: (a) GJ1, (b) GJ2, and (c) GJ3.

initial cracks extend. Before reaching the peak load, 1 or 2 main vertical cracks occurred. After reaching the peak load, the load capacity decreased abruptly, and it finally failed in a few seconds. The concrete around the main crack is crushed and fell off, and the column is destroyed.

The group ZJB consists of three columns with $1.44 \%$ of the bamboo reinforcement ratio. When the axial load reaches $70 \%$ of the peak load, initial vertical cracks appear at the upper end of the column. With the load increasing, the initial cracks extend downward. At the same time, new vertical cracks form. When approaching the peak load, several vertical cracks occur in the upper part of the column and divide the column into several minor columns. As the increase in the axial load continues, the concrete of the small columns is crushed, and the specimen is destroyed. In this group of specimens, the bamboo bars yield first, and then the concrete in the compression zone is crushed. There are visible signs before failure. Figure 8 indicates the failure patterns of specimens ZJB.

The group ZJC consists of three columns, with $2.56 \%$ of the bamboo reinforcement ratio. The axial load reaches about $65 \%$ of the peak load, and initial cracks appear simultaneously in the upper, middle, and lower parts of the column. As the load increases, the initial cracks extend, and multiple new cracks appear. When reaching the failure load, the concrete around the main crack is crushed and fell off, and the specimen is damaged. The main cracks of these columns penetrate almost along the column before failure. These specimens have visible signs before failure, as well as specimens ZJB. The specimens ZJB and ZJC show more ductile behavior than the specimens ZJA. This stems from the fact that the columns are adequately reinforced by 


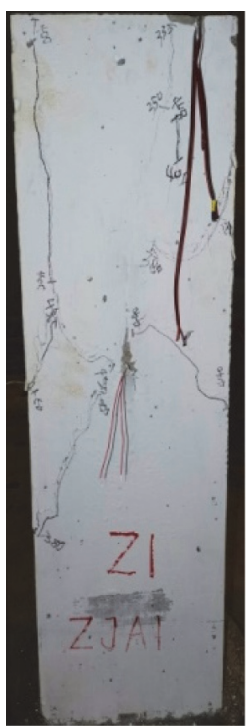

(a)

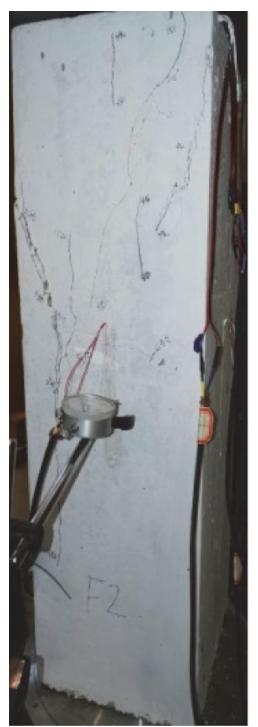

(b)

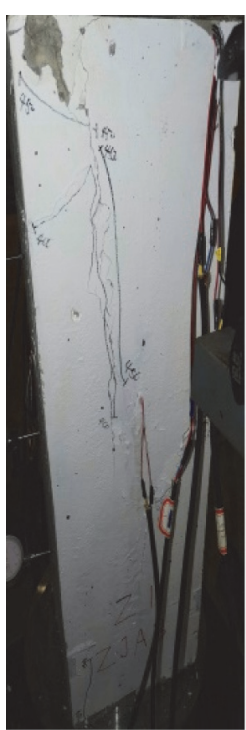

(c)

Figure 7: Failure patterns of specimens ZJA: (a) ZJA1, (b) ZJA2, and (c) ZJA3.

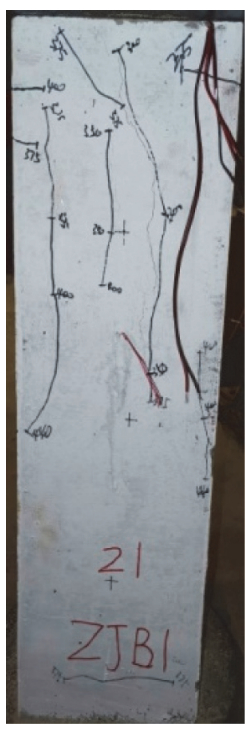

(a)

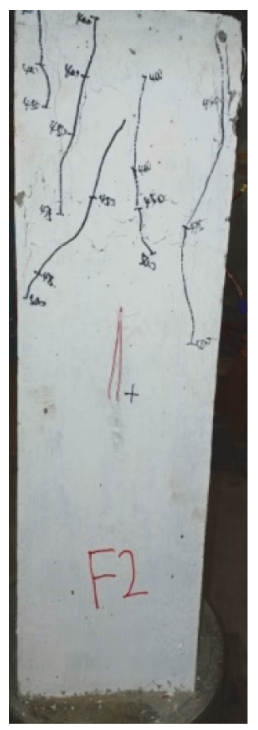

(b)

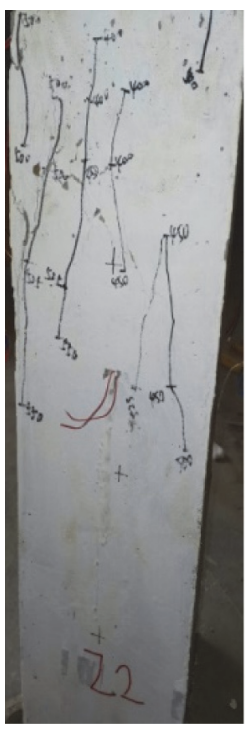

(c)

FIgUre 8: Failure patterns of specimens ZJB: (a) ZJB1, (b) ZJB2, and (c) ZJB3.

bamboo bars. The failure patterns of the specimens ZJC are shown in Figure 9.

\subsection{Axial Bearing Capacity and Ductility Index.} Experimental results are shown in Table 3. The axial load and axial deformation of each group are adopted as an average of three specimens. Define three key loads: cracking load, peak load, and failure load. The cracking load is the axial load when visible cracks appear on the specimen. The peak load is the maximum axial load that the specimen can bear. The failure load is the axial load when unloading below $85 \%$ of the peak load. We could observe the following:
(1) The cracking loads of specimens ZJA are the biggest, and the cracking load of the specimens ZJC is the smallest. It is shown that the larger the bamboo bars' cross section, the smaller the cracking load of the bamboo reinforced concrete column. The relationship between the cross-sectional area of a bamboo bar and the cracking load is shown in Figure 10.

(2) The increase of the bamboo reinforcement ratio does not significantly improve the bearing capacity of the specimens. The reinforcement ratio of ZJC is higher than that of ZJB. However, because the specimens ZJC have lower concrete strength than the specimens ZJB, the bearing capacity of the specimens ZJC is 


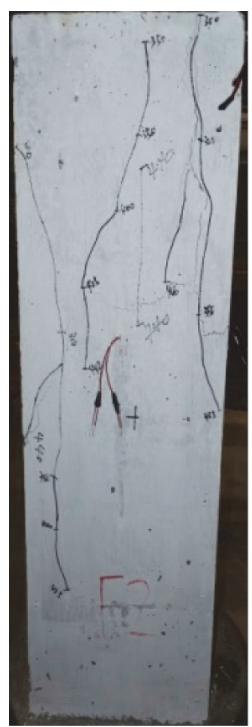

(a)

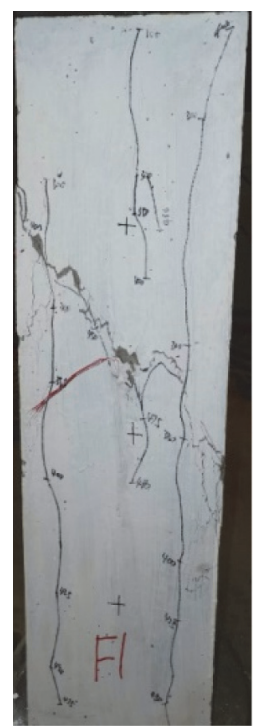

(b)

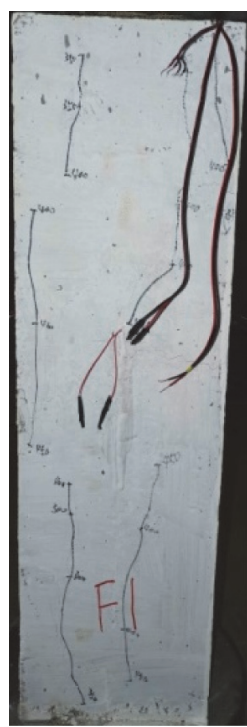

(c)

FIGURE 9: Failure patterns of specimens ZJC: (a) ZJC1, (b) ZJC2, and (c) ZJC3.

TABLE 3: Test average and calculation results.

\begin{tabular}{lcccccc}
\hline Specimen group & $P_{\mathrm{c}}(\mathrm{kN})$ & $\Delta_{\mathrm{c}}(\mathrm{mm})$ & $P_{p}(\mathrm{kN})$ & $\Delta_{\mathrm{p}}(\mathrm{mm})$ & $P_{f}(\mathrm{kN})$ & $\Delta_{\mathrm{f}}(\mathrm{mm})$ \\
\hline GJ & 333.33 & 1.438 & 583.33 & 4.162 & 493.33 & 4.959 \\
ZJA & 350 & 1.773 & 450 & 3.355 & 373.33 & 4.156 \\
ZJB & 333.33 & 1.498 & 475 & 3.224 & 410.67 & 4.413 \\
ZJC & 300 & 1.508 & 441.67 & 4.254 & 366.67 & 5.189 \\
\hline
\end{tabular}

$P_{c}$ : cracking load; $\Delta_{c}$ : axial deformation at cracking load; $P_{p}$ : peak load; $\Delta_{\mathrm{u}}$ : axial deformation at peak load; $P_{f}$ failure load; $\Delta_{f}$ axial deformation at failure load; $\mu$ : ductility index.

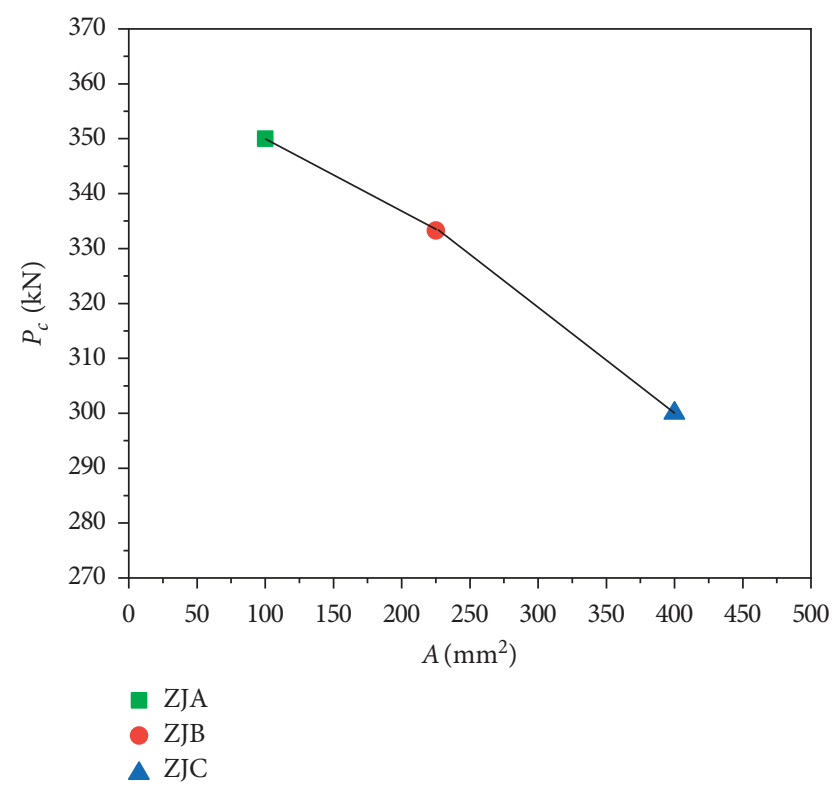

Figure 10: Cross-sectional area of a bamboo bar and cracking load curves.

lower than that of the specimens ZJB. It is demonstrated that the axial load-bearing capacity of bamboo reinforced concrete columns mainly depends on concrete strength. Figure 11 shows the concrete strength and peak load curves.

(3) The ductility of reinforced concrete structural members is defined as their deformability from yielding to maximum bearing capacity. Ductility is used to measure the inelastic deformation capacity of structural members or materials. To reflect the ductility of the axially compressed column, define ductility index $\mu=\Delta_{\mathrm{p}} / \Delta_{\mathrm{c}}$. Table 3 shows that the ductility index of the specimens ZJC is close to that of the specimens GJ and higher than that of the specimens ZJB; the specimens ZJA have the lowest ductility index. Figure 12 presents the bamboo reinforcement ratio and ductility index curves. It can be observed from Figure 12 that the ductility index of specimens ZJA, ZJB, and ZJC increases with the reinforcement ratio. Bamboo bars are used in lowstrength concrete columns to increase their ductility.

3.3. Axial Load-Axial Deformation. The axial load-axial deformation curves of the specimens are plotted in Figure 13. The axial load and axial deformation of each group are adopted as an average of three specimens. The axial deformation of each specimen is the average value measured from the two displacement meters, while the axial load is recorded by the force sensor. For the four groups, the axial 


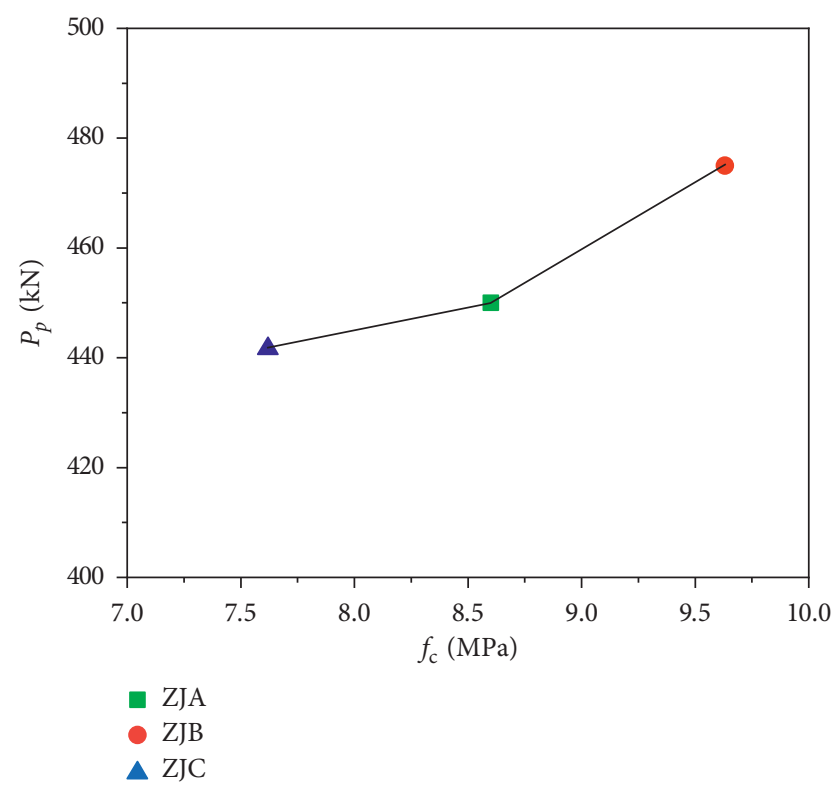

FIGURE 11: Concrete strength and peak load curves.

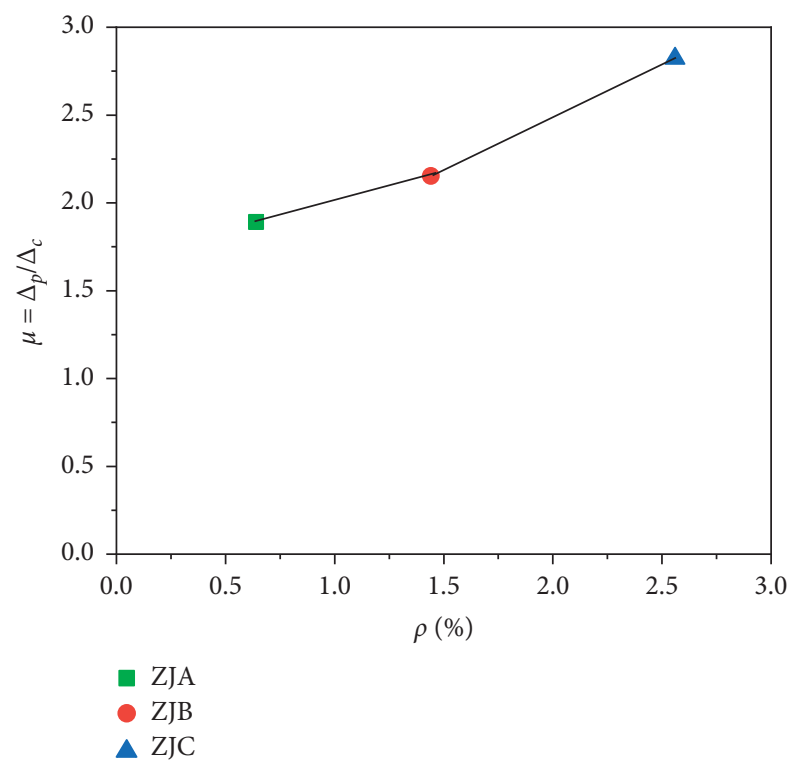

Figure 12: Bamboo reinforcement ratio and ductility index curves.

load-axial displacement curves could be divided into three stages, i.e., elastic stage, elastic-plastic stage, and failure stage.

During the elastic stage, the axial deformation of specimens GJ, ZJB, and ZJC increases linearly with the increase of axial load. Because ZJA has the lowest reinforcement ratio, the axial load-axial deformation curve exhibits certain plastic properties. The initial stiffness of ZJC is the smallest since the concrete strength is the lowest. The elastic stiffness of GJ and that of ZJB are close.

Once the outer concrete begins to crack, the curves show nonlinear behavior, and the axial deformations of the columns accelerate. All columns enter the elastic-plastic stage.

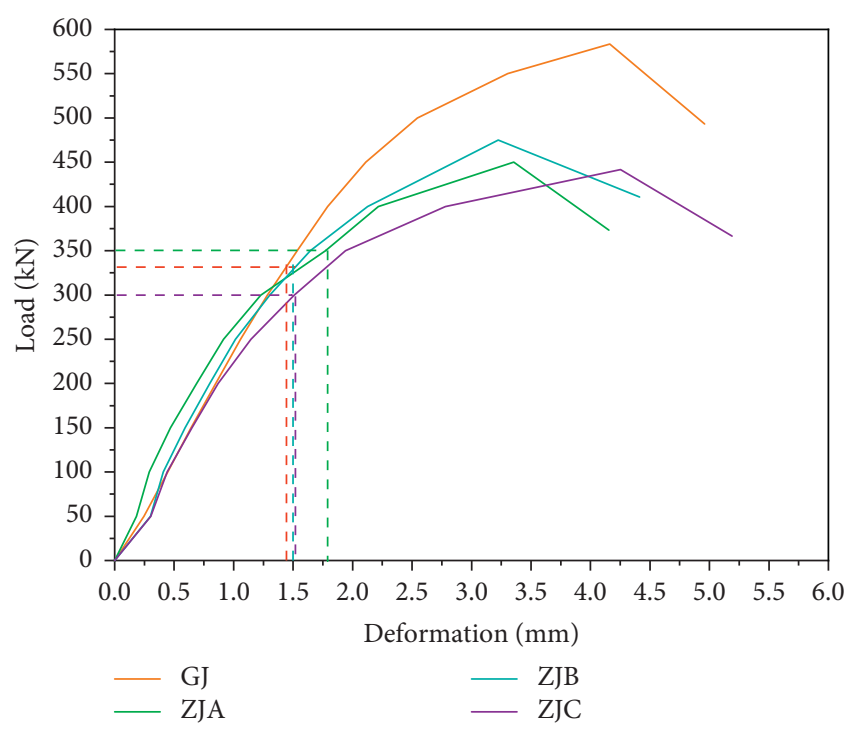

FIgURE 13: Axial load-axial deformation curves.

Because the ZJC has the most massive reinforcement ratio, the elastic-plastic stage of the curve is the longest. Before reaching the peak load, the ZJC has the most massive axial deformations, and the cracks develop sufficiently.

After the peak load, the axial load-axial deformation curves enter the failure stage. The curve slopes of the bamboo reinforced concrete columns are slightly larger than that of the reinforced concrete column. It is shown that the bamboo scrimber longitudinal bars can improve the brittleness of concrete in the failure stage.

3.4. Strain Analysis. Figure 14(a) shows the load and strain curves of GJ specimens. When the axial compressive load is not so large, the steel bars and concrete are in the elastic stage, and the compressive strain increases linearly with the increase of the load. The strain increasing rate of concrete is higher than the steel bars. It indicates that the bonding strength between the steel bars and the low-strength concrete is low, and there is slippage between the steel bars and concrete. The cooperative performance of the low-strength concrete and the steel bars is poor. After the concrete column cracks, the specimen gets into the elastoplastic stage. The strain increase of concrete and load shows a nonlinear relationship, and the strain increasing rate of concrete is much faster than the load increasing rate. With the increase and development of cracks, the compressive strain of concrete increases rapidly, while the compressive strain of the steel bars grows evenly. The difference in compressive strain between the concrete and the steel bars further increases. At failure load, the concrete in the upper part of the column is crushed, and the longitudinal steel bars do not yield.

Figures 14(b)-14(d) are the load and strain curves of specimens ZJA, ZJB, and ZJC, respectively. When the axial compressive load is minor, the load and the compressive strain of the bamboo scrimber reinforced concrete column are approximately linear. The strain of the longitudinal 


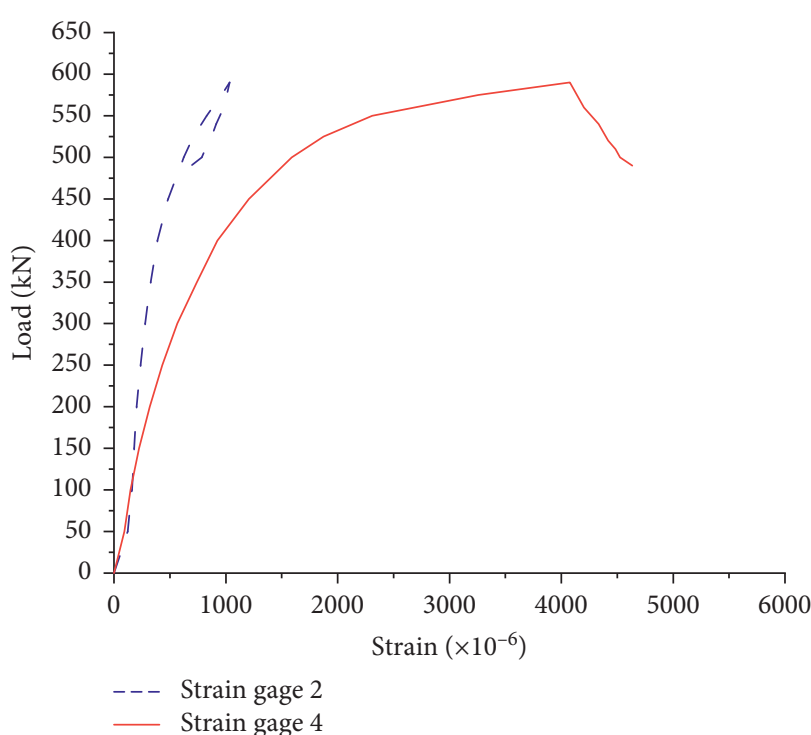

(a)

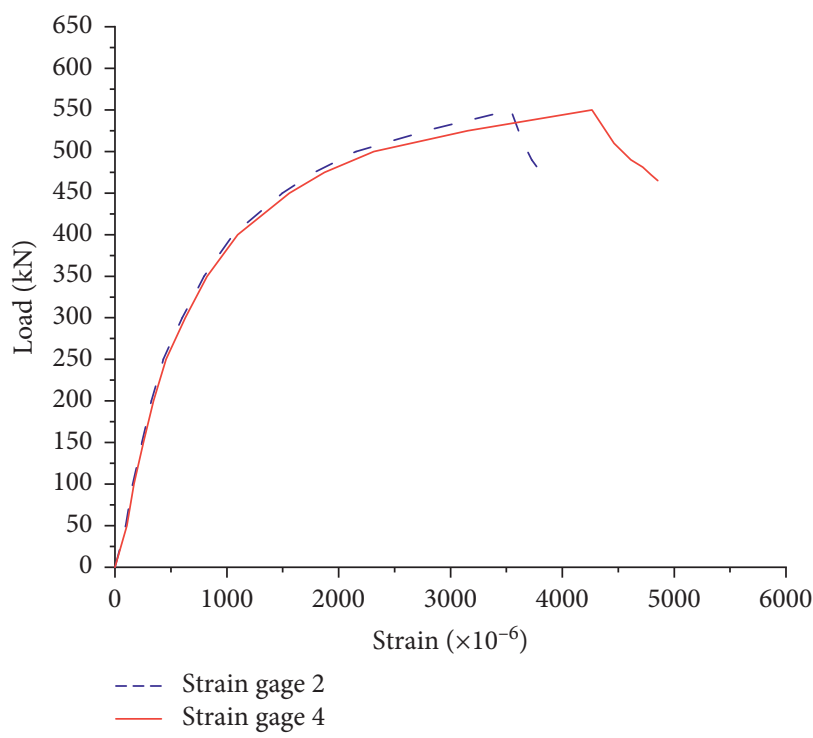

(c)

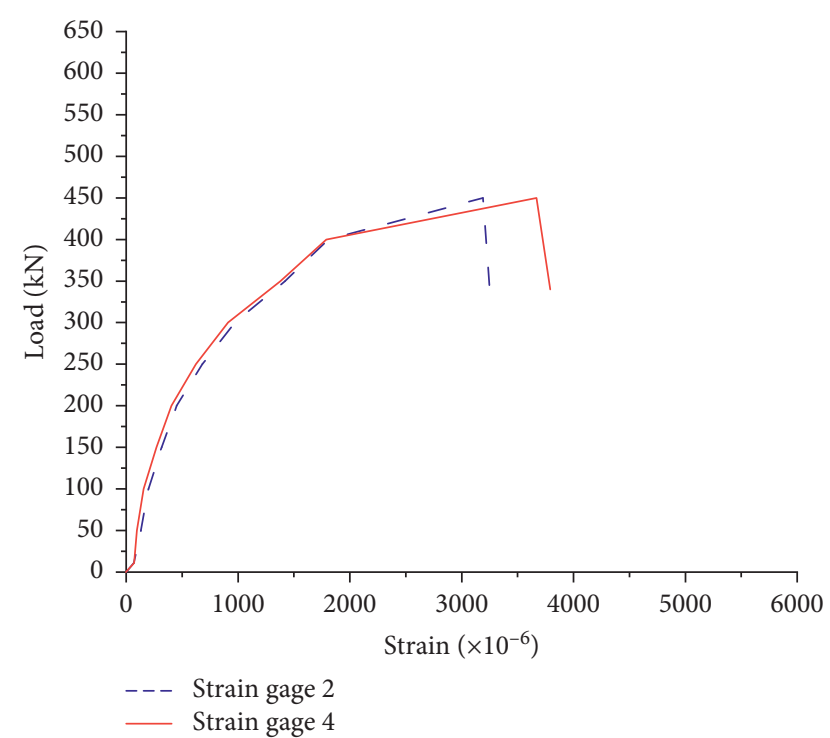

(b)

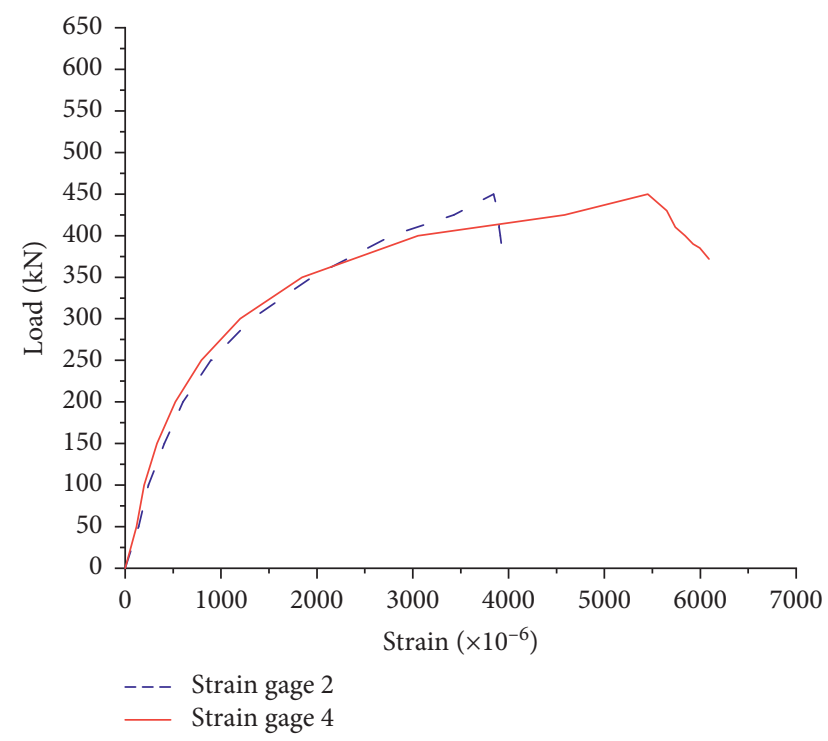

(d)

FIGURE 14: Load and strain curves of specimens: (a) GJ, (b) ZJA, (c) ZJB, and (d) ZJD.

bamboo bars is almost the same as the compressive strain of the concrete column, which indicates that the bond strength between the treated bamboo bars and the low-strength concrete is high, and the cooperative performance is excellent. The bonding force of bamboo bars and concrete is composed of two parts: one is the gripping force generated by the shrinkage of concrete during the setting and hardening process; the other is the interlocking force caused by the friction between the rough bamboo bars and concrete. The bond force ensures that the bamboo bars and concrete deform together under the load. As the load increases, the concrete is cracked. Therefore, the slope of the load-strain curve becomes smaller, and the curve shows visible nonlinearity. The compressive strain of concrete is higher than that of the bamboo bars. It reflects the relative slippage between the bamboo bars and concrete.
At the peak load and failure load, the average strain of the concrete column (strain gage 4), the average strain of the longitudinal bars (strain gage 2), and the difference average of the two are compared and plotted in Figure 15. Figure 15(a) shows that the compressive strain of the concrete column of the specimens ZJC is the largest, and that of the specimens ZJA and ZJB is the smallest. The longitudinal reinforcement gives full play to the plastic properties of concrete and improves the brittleness of the short concrete columns under the axial compressive load. In terms of the contribution to the plastic properties of the concrete column, the bamboo bars with $2.56 \%$ reinforcement far exceed the steel bars with $0.72 \%$ reinforcement. Figure $15(b)$ shows that the longitudinal bars' strain of the specimens ZJC is the largest, and that of the specimens GJ is the smallest. Obviously, in the short low-strength concrete columns, the 


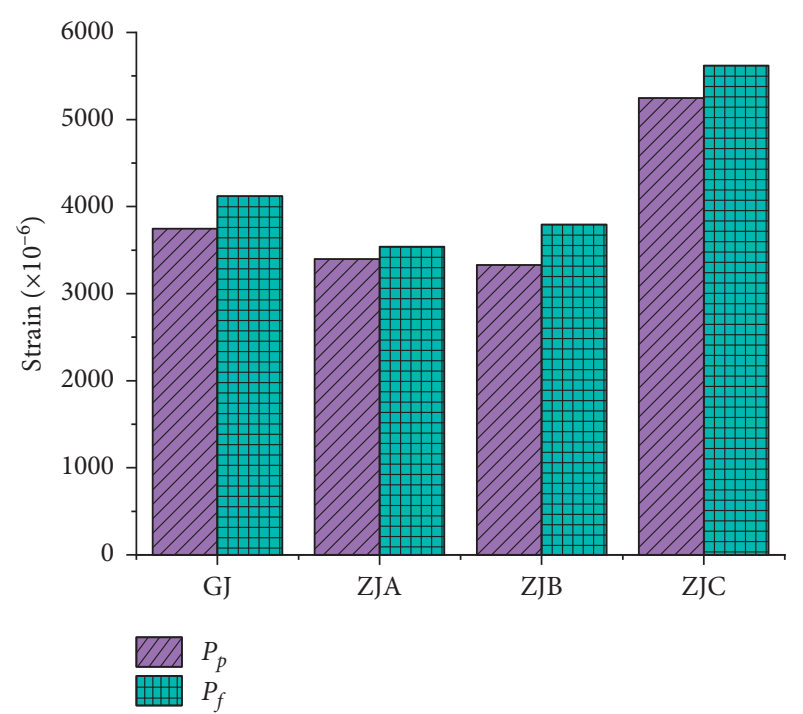

(a)

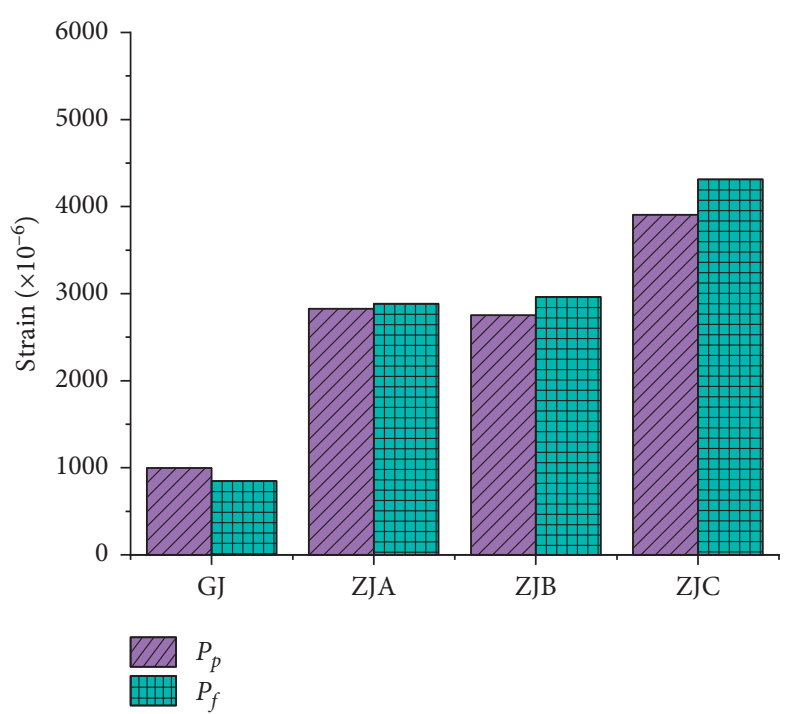

(b)

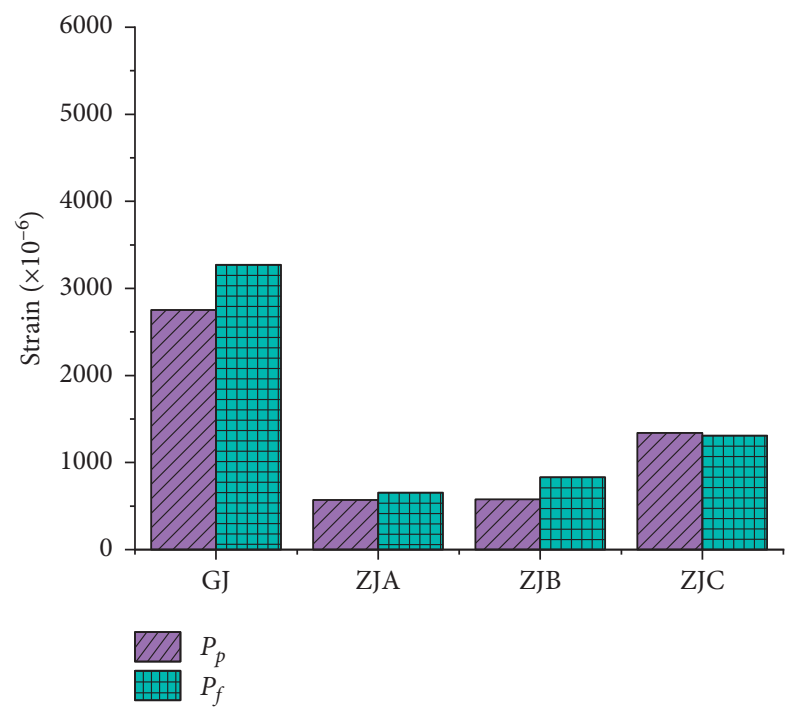

(c)

FIGURE 15: Comparison diagram of strain: (a) average strain of concrete column; (b) average strain of longitudinal bar; (c) difference average of concrete column' strain and longitudinal bar.

strength of the steel bars is not fully developed, and the strength of the bamboo bars is developed more sufficiently. Figure 15(c) shows that the difference between the concrete' strain and the longitudinal bar strain of the specimens ZJA and ZJB is the smallest, and that of the specimens GJ is the largest. It can be observed that the collaborative performance of the surface-treated bamboo bars and low-strength concrete with the cross-sectional dimensions of $10 \mathrm{~mm} \times 10 \mathrm{~mm}$ and $15 \mathrm{~mm} \times 15 \mathrm{~mm}$ is the best; the collaborative performance of the bamboo bars with the cross-sectional size of $20 \mathrm{~mm} \times 20 \mathrm{~mm}$ and the low-strength concrete is second; the collaborative performance of steel bars and low-strength concrete is the weakest.

The strain distribution of longitudinal bars along with the height at the cracking load, peak load, and failure load of the specimens is shown in Figure 16. Figure 16(a) reveals that the compressive strain of the steel bar of the specimens GJ gradually decreases from top to bottom at the cracking load; at the peak load, the compressive strain of the upper part of the steel bar hardly changes, and the compressive strain of the lower half of the steel bar slightly decreases. The cracks of the specimens GJ mainly concentrate in the upper section. After cracking, there is almost no stress transfer between the steel bars and the concrete. The steel strain at the failure load is slightly smaller than that at the ultimate bearing capacity. The steel bar is in the elastic deformation stage during the whole stress stage. The strain distributions of specimens ZJA are plotted in Figure 16(b). At the cracking load, the compressive strain of the bamboo bar is a linear distribution from top to bottom, and the bonding performance of the bamboo bar and concrete is excellent. At the peak load, the slope of the strain curve of the bamboo bar 


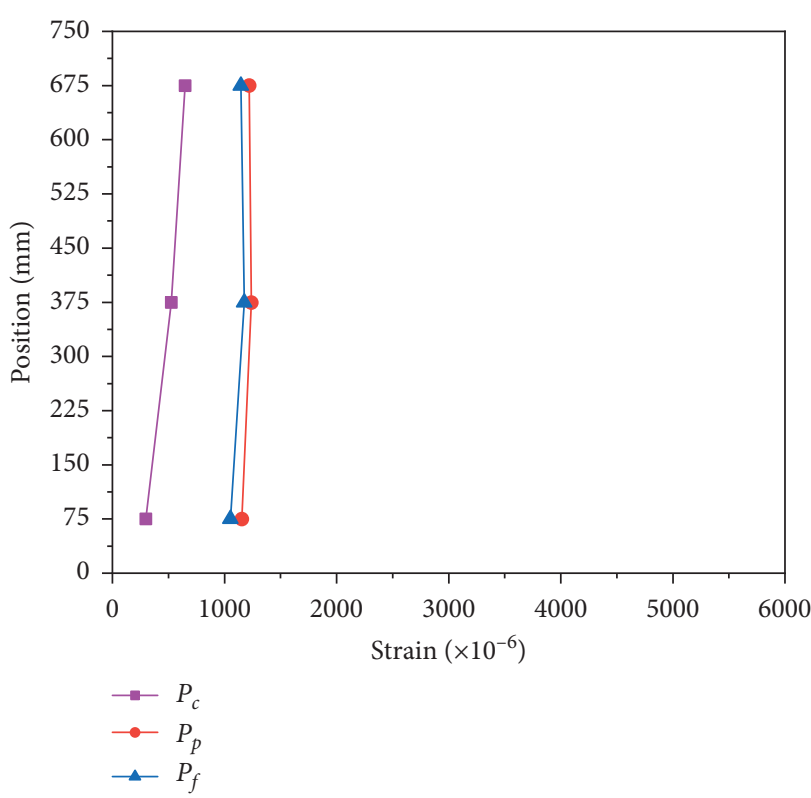

(a)

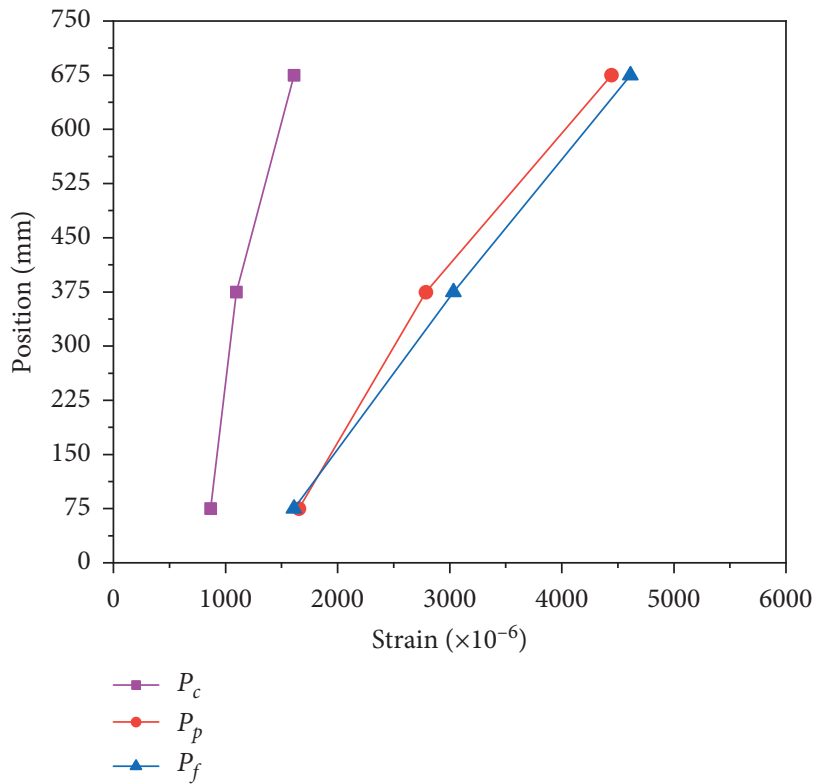

(c)

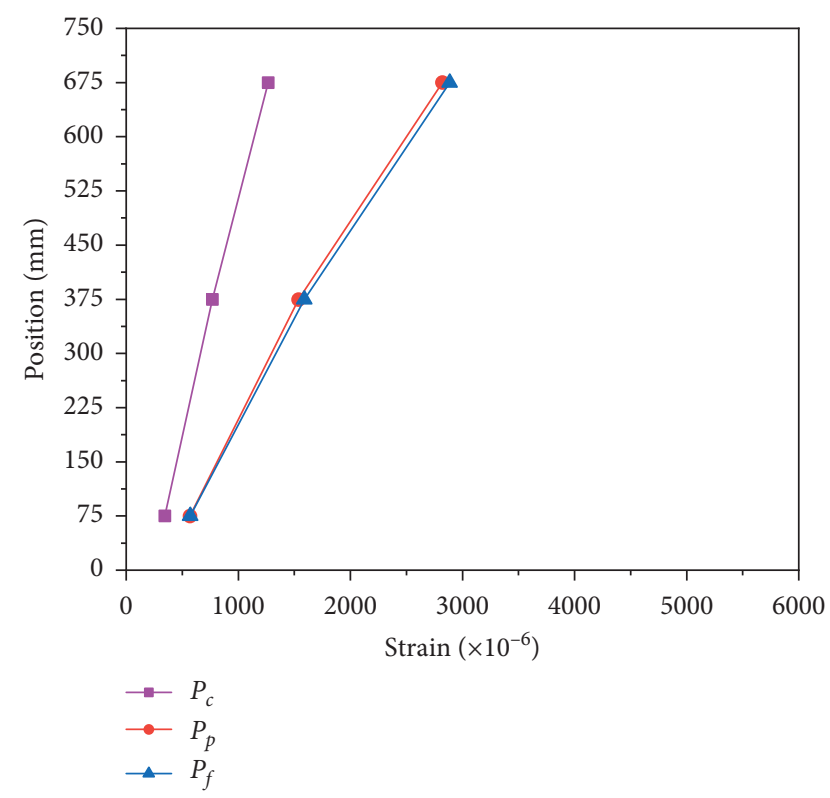

(b)

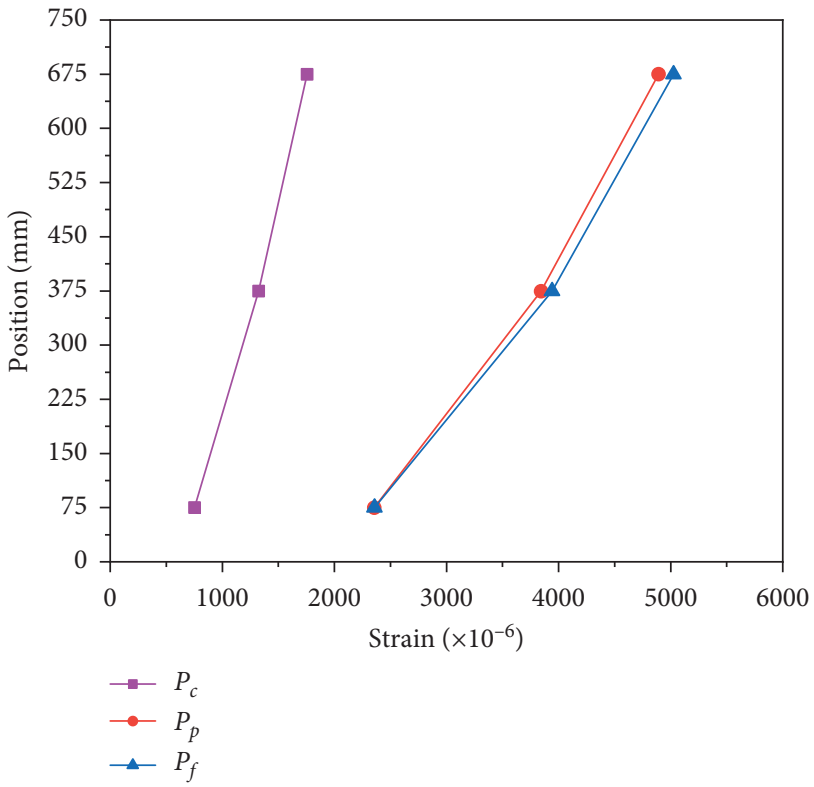

(d)

FIGURE 16: Strain distribution of longitudinal reinforcement: (a) GJ, (b) ZJA, (c) ZJB, and (d) ZJC.

decreases, and the growth rate of the bamboo bar strain speeds up. In the failure stage, the increment of the compressive strain of the bamboo bar is small. Figures 16(c) and 16(d) are, respectively, strain distribution of specimens ZJB and ZJC. At cracking and peak load, the compressive strain distribution of bamboo bar in specimens ZJB and ZJC is the same as that in specimens ZJA. The compressive strain of the bamboo bar has significantly increased from the cracking load to the peak load. From the peak load to the failure load, the strain increasing values of the top and middle bamboo bar of the specimens ZJB are, respectively, 3.5\% and 8.5\%. This shows that there is still some bond between the bamboo bar and concrete. From the peak load to the failure load, the increase of compressive strain of the specimens ZJC in the upper and middle of the bamboo bar is tiny. This indicates that the bonding performance between bamboo bar and concrete reduces.

\section{Conclusions}

In this study, the feasibility of using bamboo scrimber as the reinforcing material in low-strength concrete columns has been evaluated through the axial compressive experiments. Twelve column specimens are conducted under axial loads. By analyzing and comparing the experimental results, the following conclusions are drawn. 
The bamboo scrimber bar has high bonding strength with concrete after the surface treatment. The collaborative working performance between bamboo and concrete is excellent. The increase of the bamboo reinforcement ratio cannot significantly improve the ultimate bearing capacity of the specimens. The axial bearing capacity of bamboo scrimber reinforced low-strength concrete columns mainly depends on concrete strength. The cracking load of the concrete column with $10 \mathrm{~mm} \times 10 \mathrm{~mm}$ or $15 \mathrm{~mm} \times 15 \mathrm{~mm}$ bamboo scrimber reinforcement is higher than that of the concrete column with $20 \mathrm{~mm} \times 20 \mathrm{~mm}$ bamboo scrimber reinforcement. Besides, the cooperative working performance of $10 \mathrm{~mm} \times 10 \mathrm{~mm}$ or $15 \mathrm{~mm} \times 15 \mathrm{~mm}$ bamboo bars and low-strength concrete is better than that of $20 \mathrm{~mm} \times 20 \mathrm{~mm}$ bamboo bars and low-strength concrete. The bamboo scrimber bars act as longitudinal bars under axial load, which can give full play to the plasticity of lowstrength concrete. The strength of steel bars in low-strength concrete columns cannot be brought into play. With the increase of the bamboo reinforcement ratio, the ductility of bamboo reinforced concrete columns increases. The ductility of the concrete column with $2.56 \%$ bamboo scrimber reinforcement is close to that of the concrete column with $0.72 \%$ steel reinforcement.

\section{Data Availability}

Some of the data used to support the findings of this study are included within the article. All datasets generated during the current study are not publicly available, because the data also form part of an ongoing study, but are available from the corresponding author on reasonable request.

\section{Disclosure}

The opinions and findings in this paper are those of authors and do not represent those of sponsors.

\section{Conflicts of Interest}

The authors declare that they have no conflicts of interest regarding the publication of this paper.

\section{Acknowledgments}

This research was financially supported by the China Scholarship Council (Grant no. CSC201908430245), the Undergraduate Research Study and Innovative Experiment Plan of Education Bureau of Hunan Province (Grant no. 2018365), the Natural Science Foundation of Hunan Province (Grant no. 2015JJ3172), and the Research Foundation of Education Bureau of Hunan Province (Grant no. 16C1664).

\section{References}

[1] C. K. Kankam, "Raffia palm-reinforced concrete beamsfia palm-reinforced concrete beams," Materials and Structures, vol. 30, no. 5, pp. 313-316, 1997.
[2] R. D. T. Filho, F. D. A. Silva, E. M. R. Fairbairn, and J. D. A. M. Filho, "Durability of compression molded sisal fiber reinforced mortar laminates," Construction and Building Material, vol. 23, no. 6, pp. 2409-2420, 2009.

[3] H. K. Chow, Bamboo as Material for Reinforced Concrete, Massachusetts Institute of Technology, Cambridge, MS, USA, 1914.

[4] S. Leelatanon, S. Srivaro, and N. Matan, "Compressive strength and ductility of short concrete columns reinforced by bamboo," Songklanakarin Journal of Science and Technology, vol. 32, no. 4, pp. 419-424, 2010.

[5] M. Terai and K. Minami, "Fracture behavior and mechanical properties of bamboo reinforced concrete members," Procedia Engineering, vol. 10, pp. 2967-2972, 2011.

[6] A. Agarwal, B. Nanda, and D. Maity, "Experimental investigation on chemically treated bamboo reinforced concrete beams and columns," Construction and Building Materials, vol. 71, pp. 610-617, 2014.

[7] K. Huang, J. H. Xie, L. H. Zou et al., "Experimental research on the mechanical property of new modified bamboo reinforced concrete columns under eccentric load," Journal of Basic Science and Engineering, vol. 24, no. 6, pp. 1268-1278, 2016.

[8] A. Javadian, M. Wielopolski, I. F. C. Smith, and D. E. Hebel, "Bond-behavior study of newly developed bamboo-composite reinforcement in concrete," Construction and Building Materials, vol. 122, pp. 110-117, 2016.

[9] J. X. Wang, "Bamboo scrimber-new technology, new product, China Wood Industry, vol. 3, no. 4, pp. 52-53, China, 1989.

[10] B. Sharma, A. Gatóo, M. Bock, and M. Ramage, "Engineered bamboo for structural applications," Construction and Building Materials, vol. 81, pp. 66-73, 2015.

[11] D. Huang, Y. Bian, A. Zhou, and B. Sheng, "Experimental study on stress-strain relationships and failure mechanisms of parallel strand bamboo made from phyllostachys," Construction and Building Materials, vol. 77, pp. 130-138, 2015.

[12] H. Y. Liu, M. Lei, and B.W. Chen, "Experimental study on axial compression behavior of masonry columns' strengthening with bamboo scrimber bar mesh mortar layer," Advances in Civil Engineering, vol. 2020, Article ID 3473452, 11 pages, 2020.

[13] J. G. /T. Mohurd, Testing Methods for Physical and Mechanical Properties of Bamboo Used in Building, China Architecture \& Building Press, Beijing, China, 2007. 